\title{
Emerging role of Toll-like receptor 4 in hepatocellular carcinoma
}

\author{
This article was published in the following Dove Press journal: \\ Journal of Hepatocellular Carcinoma \\ 16 February 2015 \\ Number of times this article has been viewed
}

\author{
Jing Yang' \\ Min $\mathrm{Li}^{2}$ \\ Qi Chang Zheng ${ }^{2}$ \\ 'Department of First General Surgery, \\ Gansu Provincial Hospital, Lanzhou, \\ ${ }^{2}$ Department of Hepatobiliary \\ Surgery, Union Hospital, Tongji \\ Medical College, Huazhong University \\ of Science and Technology, Wuhan, \\ People's Republic of China
}

\begin{abstract}
Toll-like receptor (TLR) signaling has been implicated in inflammatory-related cancers. The upregulation of TLR signaling in hepatocellular carcinoma (HCC) suggests that it may play an essential role in the prognosis of chronic and inflammatory diseases that ultimately culminate in HCC. Here, we provide evidence about the involvement of the TLR pathway in the initiation, progression, and metastasis of HCC. The differential expression of TLR in epithelial cells has also been discussed. In particular, we emphasize the physiological role of TLR4 in the development and pathogenesis of HCC and propose novel and promising approaches for HCC therapeutics with the aid of TLR ligands.
\end{abstract}

Keywords: hepatocarcinogenesis, inflammation, signal pathway, immune therapy

\section{Introduction}

According to the World Health Organization, hepatocellular carcinoma (HCC) is a worldwide cause of cancer-related death second to lung cancer. ${ }^{1}$ It is particularly prevalent in Southeast Asia and sub-Saharan Africa due to hepatitis B virus (HBV) or hepatitis $\mathrm{C}$ virus (HCV) infection and toxins in the food and water supply. Chronic hepatitis and cirrhosis caused by $\mathrm{HBV}$ and $\mathrm{HCV}$ infection are the major risk factors of primary HCC. ${ }^{1} \mathrm{HCC}$ can currently be treated only with surgery at the early and middle stages. The efficacies of chemotherapy and radiotherapy are far from satisfactory. Recurrence is quite common in patients with $\mathrm{HCC}$ who have had a radical resection, and the survival rate is $30 \%-40 \%$ at 5 years postsurgery. ${ }^{2}$ This is because those malignant cells developed intricate mechanisms that enable them to inhibit immune cells through the secretion of specific cytokines that create an immunosuppressive environment. ${ }^{3}$ Although many factors are involved in the pathogenesis and progression of HCC, its underlying mechanisms remain unknown. Recent research demonstrated that Tolllike receptor (TLR)4 expression levels were strongly associated with microvascular invasion and early recurrence. ${ }^{4}$ It has been reported in murine models that specific $\mathrm{HBV}$ or HCV proteins can induce HCC without other oncogenic alterations. ${ }^{5}$ The excessive compensatory proliferation of differentiated hepatocytes caused by chronic liver injury is thought to be one of the major pathogenic mechanisms underlying HCC development. 6,7

Innate immunity that is conserved through evolution represents the first line of protection against microbial pathogens. Innate immunity discriminates and eventually clears a variety of pathogens and their nonpathogenic symbiotic bacteria via patternrecognition receptors such as TLRs. TLRs detect invading microbes and recognize
Correspondence: Qi Chang Zheng Department of Hepatobiliary Surgery, Union Hospital, Tongji Medical College, Huazhong University of Science and Technology, 1277\# Jiefang Avenue, Wuhan 430022, People's Republic of China

Tel +86 27 $8535 \quad$ I623

Fax +86 278535I676

Email qc_zheng@hust.edu.cn
Journal of Hepatocellular Carcinoma 2015:2 II-17 I I

Dovepress

http://dx.doi.org//0.2147/JHC.S44515 (c) (i) (5) 2015 Yang et al. This work is published by Dove Medical Press Limited, and licensed under Creative Commons Attribution - Non Commercial (unported, v3.0) BY LCense. The full terms of the License are available at http://creativecommons.org/licenses/by-nc/3.0/. Non-commercial uses of the work are permitted without any further permisst request permission may be found at: http://www.dovepress.com/permissions.php 
intracellular anomalies to which they mount an immune response, thereby playing a cardinal role in the homeostasis of the human immune system. ${ }^{8,9}$ As an important pathogen recognition molecule, TLRs activated in the immune cells play a critical role in the host's defense and eventually lead to adaptive immune responses. ${ }^{10}$ On the other hand, TLR stimulation can also directly or indirectly enhance the immunosuppressive function of regulatory T-cells that favors tumor development. ${ }^{11-13}$ It was previously thought that TLR was mainly expressed in immune cells. However, emerging evidence suggests that TLRs are expressed in some types of tumor cells, and that signaling of TLRs can promote tumor proliferation and survival, immune evasion, and drug sensitivity. ${ }^{14,15}$ The endogenous ligands released by cellular stress or apoptotic cells can activate TLR4 and lead to aseptic inflammation. Abnormal TLR activation can jeopardize normal physiological processes and cause several inflammatory diseases, cancers, and autoimmune diseases. ${ }^{16,17}$ Research over the past decade has focused on elucidating various TLRassociated functions, intermediate molecules, and ligands. There is a well-established link between TLR-induced inflammation and cancer development and progression. ${ }^{18,19}$ Similarly, TLRs are known to play a vital role in HCC. In this review, we will focus on reports concerning TLR4 signaling and its involvement in HCC development and progression, as well as on the therapeutic benefits that could arise from TLR4 stimulation.

\section{TLR receptors, ligands, and signaling pathways}

TLRs are a family of transmembrane receptors that play a key role in innate immunity. TLRs prevent pathogenic invasion by recognizing pathogen-associated molecular patterns (PAMPs), which are highly conserved components derived from a range of microbial agents, as well as endogenous macromolecules released by injured tissue. ${ }^{20}$ To date, ten TLRs have been identified in humans. TLR localization is heterogeneous and varies from the cell surface (TLR1, TLR2, TLR4, TLR5, TLR6, TLR10, and mouse TLR11 and TLR12) to the endosomes (TLR3, TLR7, TLR8, and TLR9), ${ }^{21}$ according to PAMP localization. The two most eagerly studied TLRs are TLR2 and TLR4, the patternrecognition receptors for gram-negative and -positive bacterial products, respectively. TLR4 responds to various invading exogenous pathogens through PAMPs and recognizes the endogenous ligands from necrotic cells through damage-associated molecular patterns (DAMPs), including high-motility group box-1 (HMGB1), heat shock protein
(HSP), fibrinogen, heparin sulfate, fibronectin, hyaluronic acid, and double- and single-strand RNA. ${ }^{22}$ While these molecules are released from necrotic cells, they promote tumor cell survival by activating the TLR4 expressed on tumor cells and subsequently upregulating nuclear factor-kappa $\mathrm{B}(\mathrm{NF}-\kappa \mathrm{B})$ signaling and antiapoptotic proteins. One study found that the levels of these DAMP-derived molecules were high in the tumor microenvironment and that they induced TLR4-related chronic inflammation, leading to carcinogenesis, cancer progression, and metastasis. ${ }^{23}$ Due to alterations in gene expression and the microenvironment (such as hypoxia and malnutrition) of malignant tumors, HMGB1, as well as hyaluronan expression and secretion in tumors and inflammatory cells, are generally enhanced, which plays a potential role in tumorigenesis, growth, infiltration, and metastasis. ${ }^{24-27}$ For these reasons, we will further discuss these two endogenous TLR ligands in the context of HCC.

HMGB1 is a DNA-binding protein released from dead cells or secreted by macrophages and hepatocytes at the tumor site that is involved in gene transcription, DNA recombination and repair, and nucleosome remodeling and stabilization. ${ }^{28}$ Importantly, extracellular HMGB1 released or secreted by damaged cells has been suggested to be a signature DAMP that indicates the presence of necrosis and subsequently triggers inflammation, cell proliferation, and migration. ${ }^{29}$ Recent data suggest that HMGB1 facilitates and amplifies the inflammatory response to different cytokines and TLR agonists. ${ }^{30,31}$ Two recent studies found that HMGB1 was highly expressed in HCC tissues and cell lines, induced caspase 1 activation via the TLR4/receptor for advanced glycation endproducts (RAGE) signaling pathway, and mediated the production of various inflammatory cytokines that promote tumor invasion and metastasis. ${ }^{32,33}$ Hyaluronan is a negatively charged glycosaminoglycan with a high molecular weight that is ubiquitously distributed in the extracellular matrix. When inflammation or cell damage occurs, hyaluronan can be broken down to fragments via reactive oxygen species, which can then be recognized by TLR4 and leads to the activation of immune cells and the inflammatory response. Hyaluronan is able to stimulate chemokine production in peritoneal macrophages in the absence of CD44 through a TLR2- and TLR4-dependent mechanism. ${ }^{34}$ As a major component of the outer membrane in gram-negative bacteria, lipopolysaccharide (LPS) can bind TLR4 and trigger the downstream signaling pathways. ${ }^{35,36}$ Ligand-bound TLR4 signals through two pathways. In the myeloid differentiation 
factor 88 (MyD88)-dependent pathway, the activated TLR4 recruits the TIR domain-containing adaptor protein and MyD88, which subsequently triggers the downstream adapter proteins interleukin-1 receptor-associated kinase 4 , tumor necrosis factor (TNF) receptor-associated factor 6 , and transforming growth factor (TGF)- $\beta$-activated kinase 1 , which further activates the I kappa B kinase-NF- $\mathrm{KB}$ and mitogen-activated protein kinase (MAPK) pathways, leading to the expression of proinflammatory cytokines. In the MyD88-independent pathway, TLR4 recruits TIR domaincontaining adapter-inducing interferon- $\beta$ (TRIF) and the TRIF-related adapter molecule. TRIF indirectly activates transcription factor interferon regulatory factor (IRF)3 and NF- $\kappa \mathrm{B}$, which eventually leads to the transcription of type I interferon and interferon-related genes to contribute to antibacterial and antiviral immunity (Figure 1). ${ }^{37}$ TLR stimulation leads to the activation of NF- $\kappa$ B, MAPK, Jun $\mathrm{N}$-terminal kinases, $\mathrm{P} 38$, and extracellular signal-regulated kinase, as well as interferon regulatory factor (IRF3, IRF5, and IRF7) signaling pathways, which results in the production of inflammatory cytokines. ${ }^{38,39}$ TLR activation in antigen-presenting cells also triggers adaptive immunity.

\section{TLR4 expression in HCC and hepatocarcinogenesis}

In recent years, TLR expression in tumor tissue has been reported, which may provide an important mechanism in the recruitment of inappropriate immune enhancement and dysfunctional immunity and lead to antitumor immune tolerance. ${ }^{40-43}$ TLR4 is associated with cancer in several ways. Diverse cell lines and tissue samples derived from patients with head and neck, esophageal, gastric, colorectal, liver, pancreatic, skin, breast, ovarian, and cervical cancer have been shown to express increased amounts of TLR $4 .{ }^{40}$ In these scenarios of established cancer, TLR4 facilitates an environment that is suitable for continued cancer cell proliferation. Procancer mechanisms could include the evasion of cancer cells from immune surveillance. ${ }^{14,41-43}$ The liver may be exposed to bacteria from the intestine via the portal vein, leading to an uncontrolled innate immune system that may result in inflammatory liver disorders.

Although intestinal bacteria maintain a dynamic balance and interact with the host under normal circumstances, the significant increase in Enterobacter during chronic liver injury becomes the key pathogenic factor. ${ }^{44}$ Many liver

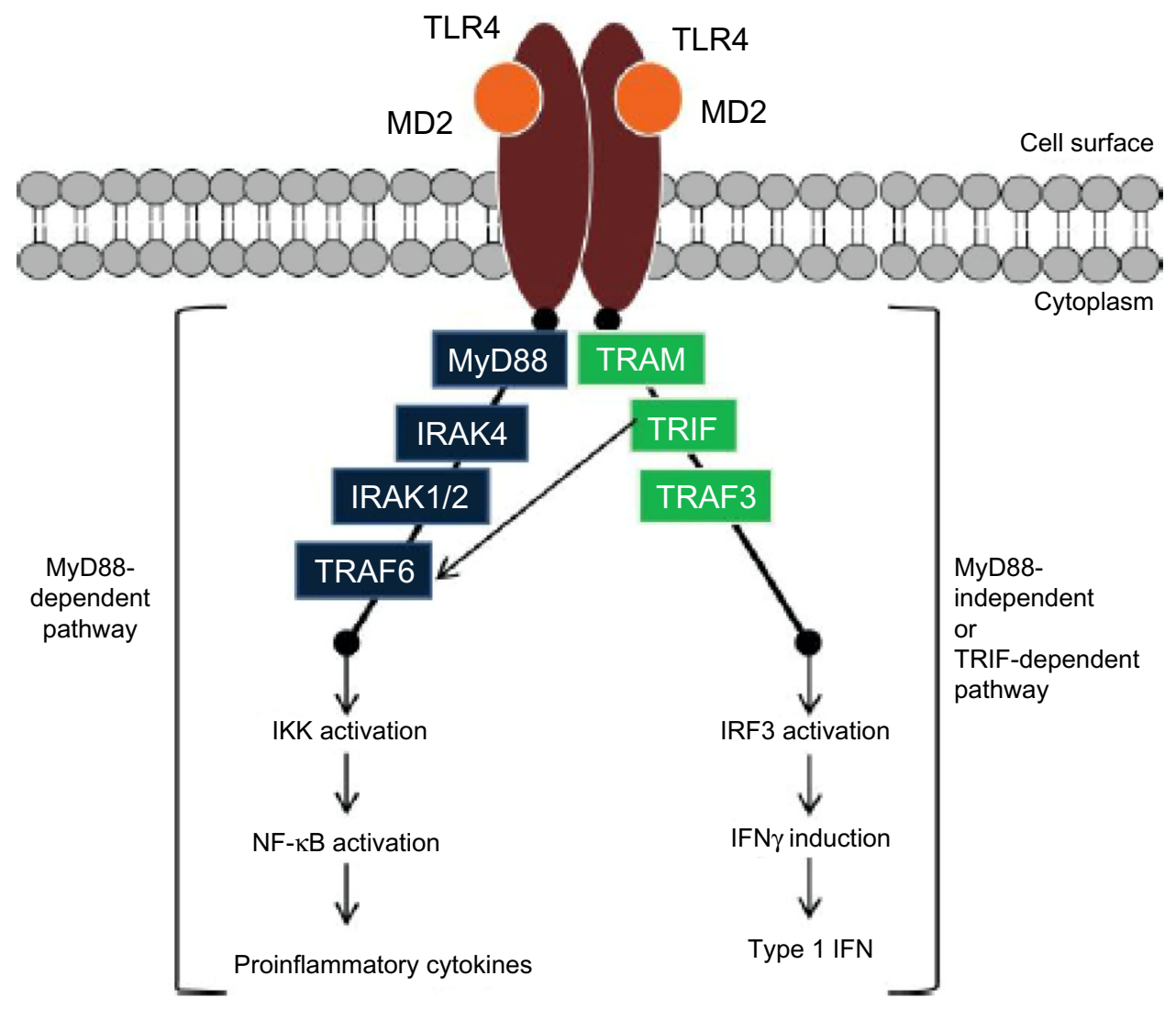

Figure I Schematic illustration of the TLR4 signaling pathway.

Abbreviations: TLR, Toll-like receptor; IRAK, interleukin-I receptor-associated kinase; IKK, inhibitor of nuclear factor-kappa B; IRF, interferon regulatory factor; NF- $\kappa B$, nuclear factor-kappa B; IFN, interferon. 
cells (Kupffer cells, hepatocytes, activated stellate cells) constantly express TLR4. ${ }^{45-48}$ Kupffer cells are specialized macrophages located in the liver. Kupffer cells are known to promote hepatic stellate cell (HSC) activation and fibrosis. Fibrosis will eventually cause cirrhosis, or loss of function of the liver. ${ }^{49,50}$ Hepatocytes that express TLR4 are responsive to LPS. Hepatocytes are also believed to play a role in the uptake of endotoxin. ${ }^{51}$ In response to liver injury, activated HSCs become the major extracellular matrix-producing cell type in the liver. HSCs interact with Kupffer cells and hepatocytes to promote liver fibrosis and inflammatory responses. ${ }^{52}$ TLR4 expression was significantly elevated in HBV- and HCV-infected livers, ${ }^{53,54}$ as well as in HCC tissues. ${ }^{55,56}$ Jing et $\mathrm{al}^{57}$ detected TLR4 expression in 106 cases of HCC patients' tissue samples; of them, 101 (86\%) showed TLR4 positivity. Further studies confirmed that LPS induced the TLR4 signaling that is involved in the invasion and metastasis of HCC and suggested that NF- $\mathrm{KB}$ may be directly activated by TLR4 signaling. ${ }^{57}$

We examined TLR4 expression in 60 patients' tumor samples and hepatoma cell lines using reverse transcription polymerase chain reaction assays. One study showed that tumor and normal tissues, as well as HepG2 and H22 cells, expressed TLR4 messenger (m)RNA. ${ }^{58}$ Another recent study demonstrated that HCC patients whose tumors expressed high levels of both TLR4 and TLR9 had a poor prognosis. ${ }^{59}$ Chronic liver damage caused by excessive inflammation due the exposure to various risk factors often results in the development of fibrosis-associated HCC. ${ }^{60}$ Since stimulation of the TLR4-signaling pathways results in the production of proinflammatory immune mediators, it is likely that TLR4 is involved in the development and progression of hepatocarcinogenesis as well. Seki et $\mathrm{al}^{24}$ confirmed that LPS/TLR4 signaling promoted liver fibrosis through two independent mechanisms. LPS/TLR4 induced HSCs to secrete chemokines that promote the chemotaxis of Kupffer cells, while TLR4-dependent signaling enhanced TGF- $\beta$ signaling by downregulating bone morphogenetic protein and activin membrane-bound inhibitor. ${ }^{24}$ Diethylnitrosamine, a carcinogen, was shown to stimulate TLR4 signaling in mice, resulting in increased tumor size and number, both of which were reduced in MyD88-deficient mice. ${ }^{61}$ Dengue-induced apoptotic hepatocytes may activate myeloid cells such as Kupffer cells, induce inflammatory cytokine production and hepatocyte mitogens via the TLR4-MyD88 pathway, and eventually promote HCC development. LPS-induced TLR4 signaling also promotes cancer cell survival and proliferation in HCC. ${ }^{62,63} \mathrm{HMGB} 1$ was secreted in response to the feeding second phase of NF- $\kappa$ B activation from HSP70 through TLR4 signaling, which may result in a higher invasion potential of hepatocarcinoma cells. ${ }^{64}$ TLR4- and MyD88-deficient mice had lower incidences of HCC and developed significantly fewer and smaller liver tumors compared to the wild-type controls, which implied that TLR4-MyD88 signaling plays a critical role in the development of HCC. ${ }^{48}$ Key mediating factors during this process seem to involve TLR-MyD88 signaling and the downstream activation of NF-кB. Collectively, TLR4-MyD88 signaling appears to be essential for hepatocarcinogenesis. Moreover, mutations or polymorphisms of the TLR4 gene are closely associated with liver carcinogenesis or malignancy. ${ }^{65}$

\section{TLR4 and the HCC microenvironment}

Malignant cells develop intricate mechanisms that enable them to secrete specific cytokines that create an immunosuppressive environment. ${ }^{3}$ Studies have correlated elevated TLR expression and dysfunctional immunity within the tumor microenvironment with cancer progression and reduced patient survival in a number of solid tumors. ${ }^{40,41}$ TLR signaling in immune cells is critical for the regulation of innate and adaptive immune responses, such as dendritic cell maturation and antigen presentation, as well as CD8+ T-cell cytotoxicity, all of which are important factors in antitumor immunity. ${ }^{10}$ TLR activation can also enhance regulatory T-cell suppressor function, favoring tumor development. Tumorassociated macrophages comprise as much as $50 \%$ of the tumor mass and provide essential support for the protumor microenvironment. ${ }^{66}$ Our study suggested that, in hepatoma cells, TLR4 may indirectly facilitate the recruitment of regulatory T-cells to the tumor site and promote intrahepatic metastasis through its interaction with macrophages. ${ }^{58}$

\section{Use of TLR4 for HCC therapy}

Recent developments in TLR-related applications for cancer therapy have made it an attractive therapeutic target. Many clinical applications using TLR agonists have met with disappointing results when used as monotherapies due to the protumor mechanisms of cancer, which uses TLR expression to facilitate immune suppression. ${ }^{67-69}$ TLR agonists have met with greater therapeutic success when used as adjuvants in combination with radiation, chemotherapy, or cancer vaccines by priming the host immunity and leading to an enhanced T-helper (TH) cell cytotoxic or TH1 response. As discussed earlier, chronic inflammation, which plays a critical role in the progression of liver disease and the development of human 
cancers, is mediated by TLR activation. Hence, the modulation of TLR4 pathways using various drugs, antibodies, microRNAs (miRNAs), and small molecules that function as TLR4 agonists and antagonists to reduce liver inflammation and prevent the progression of liver diseases toward cancer is a promising strategy to combat $\mathrm{HCC}$.

Lipid A mimetics that bind directly to TLR4-MD2 were shown to inhibit LPS-mediated activation of TLR4 signaling both in vitro and in vivo. ${ }^{67}$ A new small molecule, TAK-242, can suppress the expression of inflammatory mediators by selectively inhibiting the TLR4-mediated signaling pathway. ${ }^{68}$ Because the intestinal microbiota and TLR4 promote HCC, Schwabe et $\mathrm{al}^{69}$ found that the nonabsorbable antibiotic rifaximin could moderately reduce hepatocarcinogensis at late stages, and subsequent TLR4 activation in Kupffer cells has been suggested.

Cowden et al $^{70}$ recently tested two inhibitors of the histamine $\mathrm{H} 4$ receptor that interact with TLR4 and found that they reduced TNF- $\alpha$ production and LPS-induced inflammation in mouse livers. It has become well established over the past decade that the aberrant expression of a large number of miRNAs correlate with HCC disease severity and poor prognosis., ${ }^{2,71,72}$ In bone marrow-derived macrophages and RAW264.7 cells, interleukin-10 inhibits miR-155 expression after LPS stimulation and dampens inflammatory immune responses in a STAT-3-dependent manner. ${ }^{73}$ Although the potential of TLR4 immunomodulation for HCC immunotherapy has not yet been extensively explored, initial results from preclinical and clinical studies look promising. It is reasonable to imagine the development of a TLR4 immunomodulatory agent that reduces the inflammatory response but promotes antitumor immunity. This could be beneficial in controlling multiple stages of HCC.

\section{Conclusion}

TLRs play a critical role in innate immunity since they are expressed not only in innate immune cells, but also in nonimmune cells including cancer cells. Functional TLR4 expression has been linked to HCC development. TLR4 may serve an important role in HCC cancer tumorigenesis by promoting the malignant transformation of epithelial cells and tumor growth. The consequences might be dependent on the complex signaling networks triggered by TLR4 activation and the tumor microenvironment. A few studies have suggested TLR4 as a target in the treatment of HCC. Based on these findings, agents targeting TLR4 together with other therapies may be considered the best approaches. Above all, the mechanisms of TLR4 signaling and crosstalk with other signaling pathways in the HCC microenvironment will definitely provide a promising novel strategy for cancer treatment.

\section{Acknowledgments}

The study was supported in part by the grant from the National Natural Science Foundation of China (number 81372668) and the Fundamental Research Funds for the Central Universities (2014QN064).

\section{Disclosure}

The authors report no conflicts of interest in this work.

\section{References}

1. Bosetti C, Turati F, La Vecchia C. Hepatocellular carcinoma epidemiology. Best Pract Res Clin Gastroenterol. 2014;28(5):753-770.

2. Aravalli RN, Steer CJ, Cressman EN. Molecular mechanisms of hepatocellular carcinoma. Hepatology. 2008;48(6):2047-2063.

3. Igney FH, Krammer PH. Immune escape of tumors: apoptosis resistance and tumor counterattack. J Leukoc Biol. 2002;71(6):907-920.

4. Liu W, Jing Y, Yu G, et al. Toll like receptor 4 facilitates invasion and migration as a cancer stem cell marker in hepatocellular carcinoma. Cancer Lett. 2014. pii: S0304-3835(14)00762-9.

5. Koike K, Tsutsumi T, Fujie H, Shintani Y, Kyoji M. Molecular mechanism of viral hepatocarcinogenesis. Oncology. 2002;62 Suppl 1: 29-37.

6. Fausto N. Mouse liver tumorigenesis: models, mechanisms, and relevance to human disease. Semin Liver Dis. 1999;19(3):243-252.

7. Sakurai T, Maeda S, Chang L, Karin M. Loss of hepatic NF-kappa B activity enhances chemical hepatocarcinogenesis through sustained c-Jun N-terminal kinase 1 activation. Proc Natl Acad Sci U S A. 2006; 103(28):10544-10551.

8. Lavelle EC, Murphy C, O'Neill LA, Creagh EM. The role of TLRs, NLRs, and RLRs in mucosal innate immunity and homeostasis. Mucosal Immunol. 2010;3(1):17-28.

9. Rakoff-Nahoum S, Medzhitov R. Role of toll-like receptors in tissue repair and tumorigenesis. Biochemistry (Mosc). 2008;73(5):555-561.

10. Schreibelt G, Tel J, Sliepen KH, et al. Toll-like receptor expression and function in human dendritic cell subsets: implications for dendritic cell-based anti-cancer immunotherapy. Cancer Immunol Immunother. 2010;59(10):1573-1582.

11. Kabelitz D. Expression and function of Toll-like receptors in T lymphocytes. Curr Opin Immunol. 2007;19(1):39-45.

12. Liu H, Komai-Koma M, Xu D, Liew FY. Toll-like receptor 2 signaling modulates the functions of CD4+CD25+ regulatory T cells. Proc Natl Acad Sci U S A. 2006;103(18):7048-7053.

13. Sutmuller RP, den Brok MH, Kramer M, et al. Toll-like receptor 2 controls expansion and function of regulatory $\mathrm{T}$ cells. $J$ Clin Invest. 2006;116(2):485-494.

14. Huang B, Zhao J, Li H, et al. Toll-like receptors on tumor cells facilitate evasion of immune surveillance. Cancer Res. 2005;65(12): 5009-5014.

15. Kelly MG, Alvero AB, Chen R, et al. TLR-4 signaling promotes tumor growth and paclitaxel chemoresistance in ovarian cancer. Cancer Res. 2006;66(7):3859-3868.

16. Keogh B, Parker AE. Toll-like receptors as targets for immune disorders. Trends Pharmacol Sci. 2011;32(7):435-442.

17. So EY, Ouchi T. The application of Toll like receptors for cancer therapy. Int J Biol Sci. 2010;6(7):675-681.

18. Karin M. Nuclear factor-kappaB in cancer development and progression. Nature. 2006;441(7092):431-436. 
19. Karin M, Greten FR. NF-kappaB: linking inflammation and immunity to cancer development and progression. Nat Rev Immunol. 2005;5(10): $749-759$.

20. Takeda K, Kaisho T, Akira S. Toll-like receptors. Annu Rev Immunol. 2003;21:335-376.

21. Blasius AL, Beutler B. Intracellular toll-like receptors. Immunity. 2010;32(3):305-315.

22. Tsan MF. Toll-like receptors, inflammation and cancer. Semin Cancer Biol. 2006;16(1):32-37.

23. Sato Y, Goto Y, Narita N, Hoon DS. Cancer cells expressing toll-like receptors and the tumor microenvironment. Cancer Microenviron. 2009;2 Suppl 1:205-214.

24. Seki E, De Minicis S, Osterreicher CH, et al. TLR4 enhances TGF-beta signaling and hepatic fibrosis. Nat Med. 2007;13(11):1324-1332.

25. Tsung A, Sahai R, Tanaka H, et al. The nuclear factor HMGB1 mediates hepatic injury after murine liver ischemia-reperfusion. J Exp Med. 2005;201(7):1135-1143.

26. Tang D, Kang R, Zeh HJ 3rd, Lotze MT. High-mobility group box 1 and cancer. Biochim Biophys Acta. 2010;1799(1-2):131-140.

27. Stern R. Hyaluronidases in cancer biology. Semin Cancer Biol. 2008; 18(4):275-280.

28. Bianchi ME, Manfredi AA. High-mobility group box 1 (HMGB1) protein at the crossroads between innate and adaptive immunity. Immunol Rev. 2007;220:35-46.

29. Scaffidi P, Misteli T, Bianchi ME. Release of chromatin protein HMGB1 by necrotic cells triggers inflammation. Nature. 2002;418(6894): 191-195.

30. Sha Y, Zmijewski J, Xu Z, Abraham E. HMGB1 develops enhanced proinflammatory activity by binding to cytokines. J Immunol. 2008;180(4):2531-2537.

31. Tian J, Avalos AM, Mao SY, et al. Toll-like receptor 9-dependent activation by DNA-containing immune complexes is mediated by HMGB1 and RAGE. Nat Immunol. 2007;8(5):487-496.

32. Youn JH, Oh YJ, Kim ES, Choi JE, Shin JS. High mobility group box 1 protein binding to lipopolysaccharide facilitates transfer of lipopolysaccharide to CD14 and enhances lipopolysaccharidemediated TNF-alpha production in human monocytes. J Immunol. 2008;180(7):5067-5074.

33. Yan W, Chang Y, Liang X, et al. High-mobility group box 1 activates caspase-1 and promotes hepatocellular carcinoma invasiveness and metastases. Hepatology. 2012;55(6):1863-1875.

34. Jiang D, Liang J, Fan J, et al. Regulation of lung injury and repair by Tolllike receptors and hyaluronan. Nat Med. 2005;11(11):1173-1179.

35. Del Pozo JL. Primers on molecular pathways: lipopolysaccharide signaling - potential role in pancreatitis and pancreatic cancer. Pancreatology. 2010;10(2-3):114-118.

36. Ikebe M, Kitaura Y, Nakamura M, et al. Lipopolysaccharide (LPS) increases the invasive ability of pancreatic cancer cells through the TLR4/MyD88 signaling pathway. J Surg Oncol. 2009;100(8): 725-731.

37. Loiarro M, Ruggiero V, Sette C. Targeting TLR/IL-1R signalling in human diseases. Mediators Inflamm. 2010;2010:674363.

38. Akira S, Uematsu S, Takeuchi O. Pathogen recognition and innate immunity. Cell. 2006;124(4):783-801.

39. Lee MS, Kim YJ. Signaling pathways downstream of patternrecognition receptors and their cross talk. Annu Rev Biochem. 2007;76: $447-480$.

40. Mai CW, Kang YB, Pichika MR. Should a Toll-like receptor 4 (TLR-4) agonist or antagonist be designed to treat cancer? TLR-4: its expression and effects in the ten most common cancers. Onco Targets Ther. 2013;6:1573-1587.

41. Fu HY, Li C, Yang W, et al. FOXP3 and TLR4 protein expression are correlated in non-small cell lung cancer: implications for tumor progression and escape. Acta Histochem. 2013;115(2):151-157.

42. Tang X, Zhu Y. TLR4 signaling promotes immune escape of human colon cancer cells by inducing immunosuppressive cytokines and apoptosis resistance. Oncol Res. 2012;20(1):15-24.
43. Wang L, Zhao Y, Qian J, et al. Toll-like receptor-4 signaling in mantle cell lymphoma: effects on tumor growth and immune evasion. Cancer. 2013;119(4):782-791.

44. Seki E, Brenner DA. Toll-like receptors and adaptor molecules in liver disease: update. Hepatology. 2008;48(1):322-335.

45. Matsumura T, Degawa T, Takii T, et al. TRAF6-NF-kappaB pathway is essential for interleukin-1-induced TLR2 expression and its functional response to TLR2 ligand in murine hepatocytes. Immunology. 2003;109(1):127-136.

46. Paik YH, Schwabe RF, Bataller R, Russo MP, Jobin C, Brenner DA. Toll-like receptor 4 mediates inflammatory signaling by bacterial lipopolysaccharide in human hepatic stellate cells. Hepatology. 2003; 37(5):1043-1055.

47. Su GL, Klein RD, Aminlari A, et al. Kupffer cell activation by lipopolysaccharide in rats: role for lipopolysaccharide binding protein and toll-like receptor 4. Hepatology. 2000;31(4):932-936.

48. Testro AG, Visvanathan K. Toll-like receptors and their role in gastrointestinal disease. J Gastroenterol Hepatol. 2009;24(6):943-954.

49. Aoyama T, Paik YH, Seki E. Toll-like receptor signaling and liver fibrosis. Gastroenterol Res Pract. 2010;2010. pii: 192543.

50. Duffield JS, Forbes SJ, Constandinou CM, et al. Selective depletion of macrophages reveals distinct, opposing roles during liver injury and repair. J Clin Invest. 2005;115(1):56-65.

51. Seki E, Schnabl B. Role of innate immunity and the microbiota in liver fibrosis: crosstalk between the liver and gut. J Physiol. 2012;590(Pt 3): 447-458.

52. Friedman SL. Hepatic stellate cells: protean, multifunctional, and enigmatic cells of the liver. Physiol Rev. 2008;88(1):125-172.

53. Wang JP, Zhang Y, Wei X, et al. Circulating Toll-like receptor (TLR) 2, TLR4, and regulatory $\mathrm{T}$ cells in patients with chronic hepatitis $\mathrm{C}$. APMIS. 2010;118(4):261-270.

54. Wei XQ, Guo YW, Liu JJ, Wen ZF, Yang SJ, Yao JL. The significance of Toll-like receptor 4 (TLR4) expression in patients with chronic hepatitis B. Clin Invest Med. 2008;31(3):E123-E130.

55. Machida K, Tsukamoto H, Mkrtchyan H, et al. Toll-like receptor 4 mediates synergism between alcohol and HCV in hepatic oncogenesis involving stem cell marker Nanog. Proc Natl Acad Sci U S A. 2009; 106(5):1548-1553.

56. Nishimura M, Naito S. Tissue-specific mRNA expression profiles of human toll-like receptors and related genes. Biol Pharm Bull. 2005; 28(5):886-892.

57. Jing YY, Han ZP, Sun K, et al. Toll-like receptor 4 signaling promotes epithelial-mesenchymal transition in human hepatocellular carcinoma induced by lipopolysaccharide. BMC Med. 2012;10:98.

58. Yang J, Zhang JX, Wang H, Wang GL, Hu QG, Zheng QC. Hepatocellular carcinoma and macrophage interaction induced tumor immunosuppression via Treg requires TLR4 signaling. World $J$ Gastroenterol. 2012;18(23):2938-2947.

59. Eiró N, Altadill A, Juárez LM, et al. Toll-like receptors 3, 4 and 9 in hepatocellular carcinoma: Relationship with clinicopathological characteristics and prognosis. Hepatol Res. 2014;44(7):769-778.

60. Maeda S. NF-KB, JNK, and TLR signaling pathways in hepatocarcinogenesis. Gastroenterol Res Pract. 2010;2010:367694.

61. Naugler WE, Sakurai T, Kim S, et al. Gender disparity in liver cancer due to sex differences in MyD88-dependent IL-6 production. Science. 2007;317(5834):121-124.

62. Wang L, Zhu R, Huang Z, Li H, Zhu H. Lipopolysaccharideinduced toll-like receptor 4 signaling in cancer cells promotes cell survival and proliferation in hepatocellular carcinoma. Dig Dis Sci. 2013;58(8):2223-2236.

63. Yuan X, Zhou Y, Wang W, et al. Activation of TLR4 signaling promotes gastric cancer progression by inducing mitochondrial ROS production. Cell Death Dis. 2013;4:e794.

64. Gong W, Wang ZY, Chen GX, Liu YQ, Gu XY, Liu WW. Invasion potential of $\mathrm{H} 22$ hepatocarcinoma cells is increased by HMGB1-induced tumor NF-אB signaling via initiation of HSP70. Oncol Rep. 2013;30(3): 1249-1256. 
65. Minmin S, Xiaoqian X, Hao C, et al. Single nucleotide polymorphisms of Toll-like receptor 4 decrease the risk of development of hepatocellular carcinoma. PLoS One. 2011;6(4):e19466.

66. Murdoch C, Giannoudis A, Lewis CE. Mechanisms regulating the recruitment of macrophages into hypoxic areas of tumors and other ischemic tissues. Blood. 2004;104(8):2224-2234.

67. Rossignol DP, Lynn M. Antagonism of in vivo and ex vivo response to endotoxin by E5564, a synthetic lipid A analogue. J Endotoxin Res. 2002;8(6):483-488.

68. Yu P, Cheng X, Du Y, Huang L, Dong R. TAK-242 can be the potential agents for preventing invasion and metastasis of hepatocellular carcinoma. Med Hypotheses. 2013;81(4):653-655.

69. Dapito DH, Mencin A, Gwak GY, et al. Promotion of hepatocellular carcinoma by the intestinal microbiota and TLR4. Cancer Cell. 2012;21(4):504-516.
70. Cowden JM, Yu F, Challapalli M, et al. Antagonism of the histamine $\mathrm{H} 4$ receptor reduces LPS-induced TNF production in vivo. Inflamm Res. 2013;62(6):599-607.

71. Huang $\mathrm{S}, \mathrm{He} X$. The role of microRNAs in liver cancer progression. Br J Cancer. 2011;104(2):235-240.

72. Li W, Xie L, He X, et al. Diagnostic and prognostic implications of microRNAs in human hepatocellular carcinoma. Int J Cancer. 2008;123(7):1616-1622.

73. McCoy CE, Sheedy FJ, Qualls JE, et al. IL-10 inhibits miR-155 induction by toll-like receptors. J Biol Chem. 2010;285(27):20492-20498.

\section{Publish your work in this journal}

The Journal of Hepatocellular Carcinoma is an international, peerreviewed, open access journal that offers a platform for the dissemination and study of clinical, translational and basic research findings in this rapidly developing field. Development in areas including, but not limited to, epidemiology, vaccination, hepatitis therapy, pathology and

\section{Dovepress}

molecular tumor classification and prognostication are all considered for publication. The manuscript management system is completely online and includes a very quick and fair peer-review system, which is all easy to use. Visit http://www.dovepress.com/testimonialsphp to read real quotes from published authors.

\footnotetext{
Submit your manuscript here: http://www.dovepress.com/journal-of-hepatocellular-carcinoma-journal
} 